\title{
Transliteration - as translation methods
}

\author{
Nasrullayeva Umida Baxrom qizi ${ }^{1}$, Yusupova Umida Inomovna ${ }^{2}$, Zoxidova Muhayyo \\ Nasillayevna ${ }^{3}$ \\ ${ }^{1,2,3}$ Teachers of Namangan State University, Uzbekistan \\ Email:nasrullayeva_u@umail.uz
}

\begin{abstract}
This article discusses the need to demonstrate the complexity and "pitfalls" associated with the interlanguage functioning of names. It discusses the basic principles of the translation of proper names, the task is to obtain specific practical knowledge related to the features of certain names.

Keywords: foreign language, translation, English, method, translation methods, text, transcription.
\end{abstract}

\section{INTRODUCTION}

Transliteration - "a formal letter-by-word recreation of the original toxic unit using the alphabet of the translating language; literal imitation of the form of the original word. " Transliteration differs from practical transcription in its simplicity and the possibility of introducing additional characters. Transliteration is often used in compiling bibliographic indexes and in organizing catalogs, for example, when it is necessary to collect in one place a catalog a description of all the works of a domestic author in foreign languages. As a way of incorporating a foreign word into the Russian text, transliteration is less common, since transliteration greatly distorts the sound of a foreign name.Let us now consider the principle of transliteration. Transliteration is spoken about when languages use different graphic systems (for example, English, Russian, Greek, Armenian, Georgian), but the letters (or graphic units) of these languages can be put into some kind of correspondence with each other, and according to these correspondences, interlanguage transfer of proper names. Since, for example, the Latin alphabet, the Greek alphabet and the Cyrillic alphabet have a common basis, most of the letters of these two alphabets can be aligned with each other, taking into account the sounds that they regularly denote.

has both advantages and disadvantages. The advantages are obvious - the written version of the name is not distorted, its carrier has a universal, language-independent identification. (This is an important consideration - for example, the surname "Ельцин" is transmitted in English as Yeltsin, and in French as Eltsine). It is sometimes difficult to restore the original form of a foreign name or surname given to them in Russian transcription, that is, with a focus on sound rather than spelling of the name (for example, "Юнг" - Young or Jung? Lee - Leigh, Lee or Lie?).With transliteration to an even greater extent than with direct transfer, the borrowing language imposes a name on the pronunciation according to its own rules. This tendency is especially pronounced in relation to ancient and other historical and mythological names, the reading of which in Western European languages almost completely follows the rules of the host language: for example, in English Афродита (Aphrodite) - [fr 'daiti].

\section{MAIN PART}

Today transliteration in its pure form is not used in Russian language practice. The fact is that in English, French, German, Hungarian and other languages, many letters of the Latin alphabet have either changed their sound meaning, or are read non-standard in certain letter combinations and words. Therefore, transliterating them in Russian letters, if carried out sequentially, will give rise to variants of these names that are little similar when reading the originals. The practice of direct name transfer, that is, writing it in Latin letters, is permissible and real. Direct transfer was very rarely practiced, in particular during the Soviet period, but sometimes this was allowed in special scientific texts, including medical ones. For example, it was written: "As Freud noted in his work ...". Since the end of the 80s, the practice of direct transfer began to spread wider and wider. 
When borrowing proper names, their transfer can be guided by a written (graphic) form. It is possible to easily transfer the graphic form of a name without changes from text in one language to text in another language. This is most often practiced when languages use the general graphic basis of writing. This practice is adhered to in most countries using Latin graphics. In Western European languages, proper names borrowed from one language to another, as a rule, do not change the spelling: it's more convenient for readers who, thanks to this approach, can easily navigate in any written sources.

For example, when using a name in an English language text from a language whose writing is based on the Latin alphabet, the proper name does not undergo a change. Moreover, in principle, it is desirable that letters that are not in the English alphabet be reproduced.The drawback of the practice of direct transfer is that speakers of another language often cannot determine by spelling how to pronounce a foreign name proper.

\section{CONCLUSION}

Transferring the name in an unchanged form, native speakers often impose a pronunciation on the name that complies with the reading rules in their native language. For example, the French pronounce the name of Mozart (Mozart) as if it were a French naming, - [mozar]. In English, a widespread reading of the German proper name Munchhausen (Munchausen) as [mn'to:zn].

\section{REFERENCES}

1. BreusE.V. Fundamentals of the theory and practice of translation from Russian into English: Textbook. 2nd ed., Rev. and Dop.-M .: Publishing House of URAO, 2000. - 208s.

2. KazakovaT.A. The practical basics of translation.English $\square$ Russia.-Series: Learning foreign languages. - SPb.: "Soyuz Publishing House", - 2000, - 320s.

3. KomissarovV.N. Linguistics of translation - M .: International relations - 1980 - 167s.

4. LatyshevL.K. Translation course: Equivalence of translation and methods of its achievement. M.: International Relations, 1981 - 248s.

5. LatyshevL.K. Translation: problems of theory, practice and teaching methods: A book for a school teacher with in-depth study of the German language. - M .: Education - 1988. - 159p.

6. LevitskayaT.R., Fiterman A.M. Manual for translation from English into Russian. - M.: Higher School, 1973. - 136p.

7. Minyar-BeloruchevR.K. Theory and methods of translation - M .: Moscow Lyceum, 1996. 208s.

8. The world of translation, or the Eternal search for mutual understanding / A.Chuzhakin, P. Palazhchenko. - M.: R.Valent, 1999.-192s 